\section{Performance of a Sequential Reactive Barrier for Bioremediation of Coal Tar Contaminated Groundwater}

O RIOL GIBERT, *, †

A N D REW S. FERGUSON, ${ }^{\dagger}$

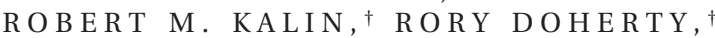

KEITH W. D I CKS O N,

KAREN L. $\mathrm{M}^{\mathrm{C}} \mathrm{GEOUGH},{ }^{\dagger}$

JAMIE ROBINSON, AND $^{\circ}$

RUSSELL THOMAS

EERC, School of Planning Architecture and Civil Engineering, Queen's University Belfast, David Keir Building, Stranmillis

Road, Belfast BT9 5AG, United Kingdom, and Parsons

Brinckerhoff Ltd., Queen Victoria House, Redland Hill, Redland, Bristol BS6 6US, United Kingdom

Following a thorough site investigation, a biological Sequential Reactive Barrier (SEREBAR), designed to remove Polycyclic Aromatic Hydrocarbons (PAHs) and BTEX compounds, was installed at a Former Manufactured Gas Plant (FMGP) site. The novel design of the barrier comprises, in series, an interceptor and six reactive chambers. The first four chambers ( 2 nonaerated-2 aerated) were filled with sand to encourage microbial colonization. Sorbant Granular Activated Carbon (GAC) was present in the final two chambers in order to remove any recalcitrant compounds. The SEREBAR has been in continuous operation for 2 years at different operational flow rates (ranging from $320 \mathrm{~L} / \mathrm{d}$ to $4000 \mathrm{~L} / \mathrm{d}$, with corresponding residence times in each chamber of 19 days and 1.5 days, respectively). Under low flow rate conditions $(320-520 \mathrm{~L} / \mathrm{d})$ the majority of contaminant removal (>93\%) occurred biotically within the interceptor and the aerated chambers. Under high flow rates $(1000-4000 \mathrm{~L} / \mathrm{d})$ and following the installation of a new interceptor to prevent passive aeration, the majority of contaminant removal $(>80 \%)$ again occurred biotically within the aerated chambers. The sorption zone (GAC) proved to be an effective polishing step, removing any remaining contaminants to acceptable concentrations before discharge down-gradient of the SEREBAR (overall removals $>95 \%$ ).

\section{Introduction}

Former manufactured gas plants (FMGP) (commonly known as 'gasworks') sites are often contaminated by coal-tar constituents. The sources of such contamination include the leakage of storage tanks, poor past practices such as on site disposal, and ineffective decommissioning of plant. The primary organic pollutants of concern at FMGP sites are polycyclic aromatic hydrocarbons (PAHs), benzene, toluene, ethylbenzene, xylene (BTEX), and other organic compounds

\footnotetext{
* Corresponding author e-mail: o.gibert@qub.ac.uk.

† Queen's University Belfast.

‡ Parsons Brinckerhoff Ltd.
}

(phenols and cresols). Inorganic species such as cyanides, sulfur compounds, and ammonium are also common constituents of concern in FMGP sites $(1,2)$. Due to the associated environmental and potential human health risks, the development of technologies to manage the risks posed by subsurface contamination in FMGP sites is of great significance (3).

Natural attenuation studies at FMGP sites have provided evidence that biodegradation of hydrocarbons may occur naturally under various environmental conditions $(2,4,5)$. Attempts to remove these contaminants have also been undertaken in enhanced in situ bioremediation programs, whereby the indigenous biological activity is stimulated by a variety of forms, including nutrients and/or additional carbon source amendments, oxygen, and/or other amendments as necessary for microbial growth $(6-8)$. However, other laboratory microcosms studies report only partial biodegradation of a few PAHs even under optimized conditions $(9,10)$.

The use of permeable reactive barriers (PRBs) for the management of complex contaminant groundwater plumes is at the very early stage of application. Few full-scale biological PRBs on FMGP sites are reported. However, reports available detail a PRB containing peat for the removal of petroleum hydrocarbons (n-alkanes and BTEX) by sorption and aerobic biodegradation processes in Southeast Australia (11) and a PRB containing aerated sand at a FMGP site in Portadown, Northern Ireland (12). A PRB for the removal of PAH and BTEX by sorption onto granular activated carbon (GAC) has also been installed in Germany (13).

The objective of this study is to examine the performance of a novel SEquential REactive BARrier (SEREBAR) on the removal of PAHs and BTEX through a combination of biodegradation and sorption processes. At present there are no published reports detailing any other sequenced biological reactive barrier technology. Therefore, the SEREBAR project provides an innovative insight into the treatment of complex contaminated groundwater at a FMGP site.

\section{Materials and Methods}

Site Description. The SEREBAR system is at a FMGP currently used for gas storage and distribution within the U.K. The FMGP site is roughly square in shape in an area of 3.5 hectares (Figure 1). The onsite production of town gas is recorded back to the 19th century, ceasing in the early 1970s. Following a thorough site investigation through a network of monitoring wells (Figure S1 in the Supporting Information) detailing hydrogeology, chemistry, and microbial ecology (15), a need to manage the risks associated with contaminant transport across site boundaries was investigated.

The site stratigraphy is composed of a made ground layer (0.9-3.4 $\mathrm{m}$ thick) underlain by Quaternary alluvial deposits of broad bands of interbedded sand, silt, and gravel (2.5-4.6 $\mathrm{m}$ thick). In turn, this is underlain by Permian breccioconglomerates and sandstones, with subordinate mudstones, and occasionally with an argillaceous or calcareous matrix. Due to a low permeability weathered zone at the top of the Permian breccia, all of the contamination found to date is within the alluvial deposits.

Groundwater flow at the site is in a southerly direction in the alluvium, with a hydraulic gradient of about 0.022 . The aquifer's hydraulic conductivity was quantified by in situ slug tests and found to be in a range of $0.3-3 \mathrm{~m} / \mathrm{d}$. The hydraulic conductivity determined at each well is shown in the Supporting Information (Table S2). 


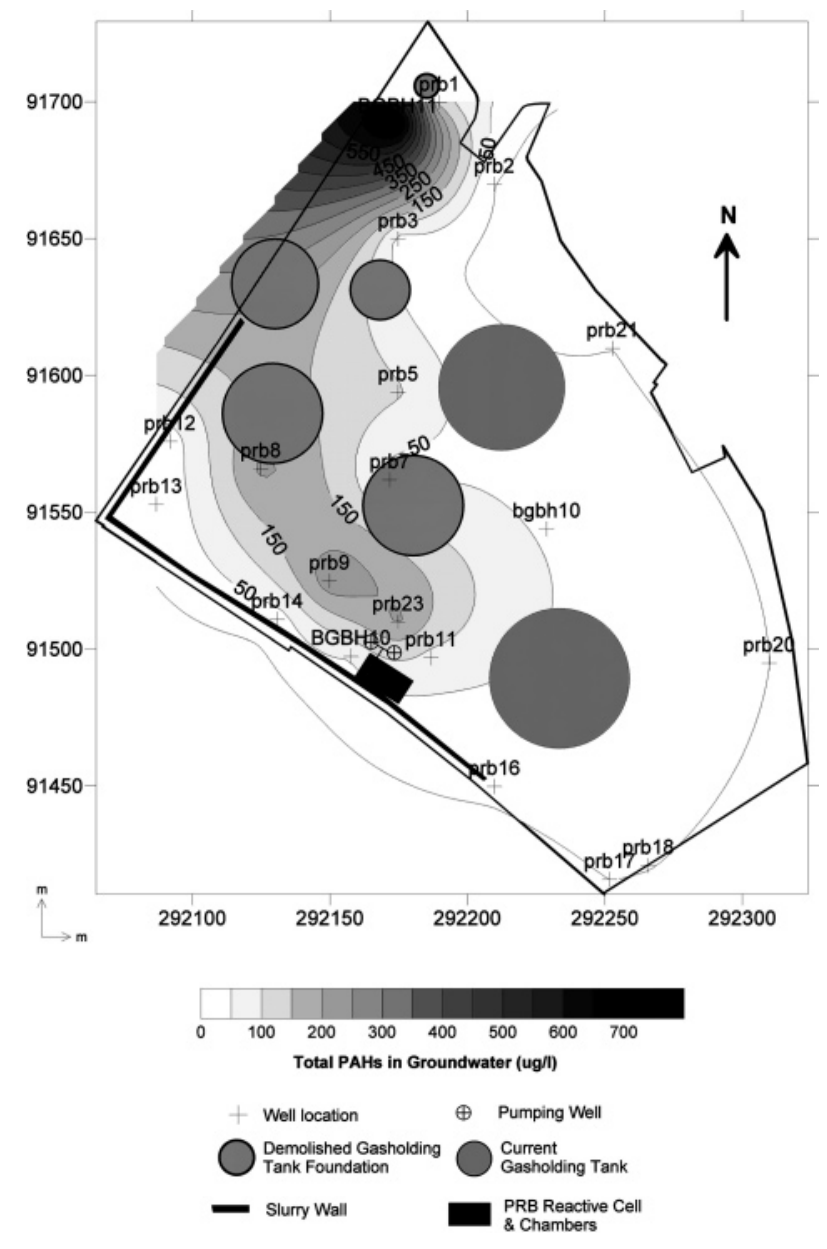

FIGURE 1. Plan of the site showing the contaminant plume and the location and configuration (funnel-and-gate) of the SEREBAR system.

Nature and Extent of Contamination. The contaminants of greatest concern found across the site were poly- and monocyclic aromatic hydrocarbons (PAHs and BTEX). Average concentrations in site soil and groundwater were 1239 $\mathrm{mg} / \mathrm{kg}$ and $0.04 \mathrm{mg} / \mathrm{L}$ (PAHs) and $11.5 \mathrm{mg} / \mathrm{kg}$ and $<0.01$ $\mathrm{mg} / \mathrm{L}$ (BTEX), respectively. Relatively high concentrations were also detected for phenols $(1.4 \mathrm{mg} / \mathrm{kg}$ and $0.02 \mathrm{mg} / \mathrm{L})$ and cresols $(5.6 \mathrm{mg} / \mathrm{kg}$ and $0.07 \mathrm{mg} / \mathrm{L})$ and for inorganic compounds such as ammonium $(27.9 \mathrm{mg} / \mathrm{kg}$ and $21.2 \mathrm{mg} / \mathrm{L})$ and cyanide ( $58.5 \mathrm{mg} / \mathrm{kg}$ and $12.1 \mathrm{mg} / \mathrm{L})$. The latter was found primarily as nontoxic iron-complexed cyanide $\mathrm{Fe}_{4}\left[\mathrm{Fe}(\mathrm{CN})_{6}\right]_{3}$ (over $94 \%$ of total cyanide), and its implication in the groundwater remediation strategy was minimal (14).

The spatial distribution of PAHs and other contaminants within the groundwater suggested that source areas are the foundations of demolished gas-holding tanks (values up to $>500 \mu \mathrm{g} / \mathrm{L}$ ) (Figure 1). This distribution is due to the foundations leaking nonaqueous phase liquids (NAPLs) that accumulated within a depression in the alluvial gravel aquifer. No information as to whether the contaminant plume was an expanding plume, stable, or shrinking plume was available; however, due to the proximity of the plume to the site boundary, it was decided that some form of encapsulation was required.

An extensive microbiological survey across the site revealed that a complex polymicrobial community of microorganisms was present throughout the site. In general, for soil core samples a more diverse bacterial population coupled with the lowest organic pollution indicated that elevated concentrations of organic contaminants were a clear cause of death of microorganisms onsite (15).

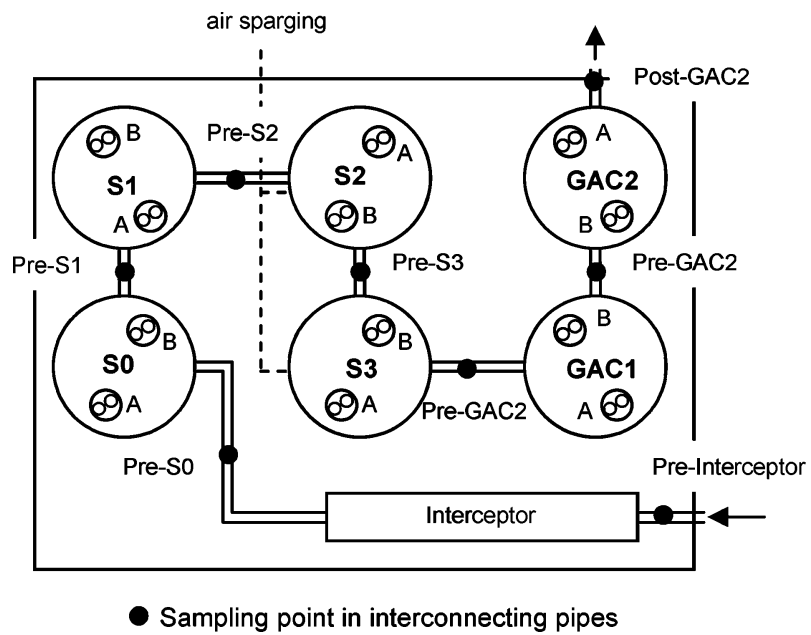

FIGURE 2. Conceptual design of the reactive gate in the SEREBAR barrier and the location of the sampling points ( $A$ and $B$ ).

Design and Construction of SEREBAR. Prior to the fullfield installation of the SEREBAR, an extensive bench-scale laboratory study was conducted to evaluate the feasibility of the system. This study included (1) microcosm experiments to ascertain the capacity of the indigenous microorganisms in degrading organic contaminants, (2) evaluation of the capacity of GAC to sorb organic pollutants, and (3) simulation of the barrier by continuous flow systems (column experiments and pilot biobarriers) (paper in preparation). Briefly, the degradation assays demonstrated that indigenous microorganisms were capable of significantly degrading BTEX, styrene, and naphthalene (BTEXSN) with first-order linear biodegradation rate constants $(k)$ ranging from $0.011 \mathrm{~h}^{-1}$ (benzene) to $0.156 \mathrm{~h}^{-1}$ (ethylbenzene). Breakthrough curves from column experiments showed a GAC sorption capacity ranging from $1.0 \mathrm{mg} / \mathrm{g}$ (styrene) to $25.2 \mathrm{mg} / \mathrm{g}$ (BTEX).

The site data obtained were used to produce a numerical groundwater model. The model, using Visual MODFLOW and MT3DMS, provided a simple, single layer, unconfined representation of the groundwater system, within which likely contaminant pathways were plotted from potential source areas. Based on these simulations, the preferred SEREBAR configuration provided by the modeling process suggested that one single gate and a slurry wall $245 \mathrm{~m}$ long should be adopted (Figure 1).

The first section of the slurry wall extends along the southern site boundary $(175 \mathrm{~m})$, while the second section extends along the site boundary in a northeastly direction $(70 \mathrm{~m})$. The wall was constructed from a low permeability cement bentonite grout $\left(<1 \times 10^{-9} \mathrm{~m} / \mathrm{s}\right)$ and is approximately $0.6 \mathrm{~m}$ wide except within the area of the gate, where it is widened to $1 \mathrm{~m}$. The wall is keyed into the weathered breccia, with a depth varying from 6 to $8 \mathrm{~m}$. In this configuration the cutoff walls (the funnel) modify flow patterns so that all contamination is captured and groundwater flows through the highly conductive SEREBAR reactor (the gate) (Figure S3 in the Supporting Information).

The gate of the SEREBAR is entirely below ground level and composed of an interceptor and six steel chambers (each $2.5 \mathrm{~m}$ diameter, $3.1 \mathrm{~m}$ height, and $4.8 \mathrm{t}$ weight) installed in series and connected by pipework (Figure 2). The function of the interceptor is to cope efficiently with nonaqueous phase liquids (NAPLs), which can clog and render the barrier media ineffective. In the interceptor, NAPLs are separated from water through differences in density. The original interceptor consisted of a nonsealed, brick structure $(5.1 \mathrm{~m}$ long, $1.3 \mathrm{~m}$ high, and $0.5 \mathrm{~m}$ wide) that permitted the intrusion of air. The first and second chambers (hereafter referred as S0 and S1) were designed to degrade organic compounds under anaer- 
obic conditions. They were filled with sand to a height of 2.5 $\mathrm{m}$, since previous lab-feasibility experiments demonstrated that the sand was colonized by a large number of indigenous microorganisms with the potential of degrading organic contaminants (paper in preparation). The hydraulic conductivity of the sand was 1 order of magnitude greater than the average hydraulic conductivity of the aquifer.

The third and fourth chambers (S2 and S3), also filled with sand, were designed to degrade organic compounds under aerobic conditions. An air sparging system was set up in these chambers to oxygenate the groundwater. The fifth and sixth chambers (GAC1 and GAC2) were filled with a commercial granular activated carbon (GAC) (Aquasorb 101, $12 \times 40$ USS, Jacobi, U.K.), which acts as a powerful sorbent for organic compounds.

The sequence of the six chambers is justified by the fact that if most compounds are degraded in chambers S0-S3, there would be less competition for sorption sites in GAC1 and GAC2, thus enhancing the sorption operation capacity of the GAC. The benefit of this sequence has also been reported in lab studies (16).

Two abstraction wells were installed up-gradient of the reactive gate for a more efficient capture of the plume. The use of abstraction wells, instead of making the groundwater flow under its natural hydraulic gradient, is justified by the fact that the contaminated aquifer is encountered at a depth that escalated construction costs in relation to the implementation of the SEREBAR system. Furthermore, the use of a pump allowed the direct control of groundwater flow through the treatment barrier, enabling perturbations to the system to be assessed and future optimization of groundwater treatment. The intercepted groundwater is then directed to the gate by means of a submersible pump, which lifts water to the interceptor, from where groundwater flows under gravity downward through the six reactive chambers. At the exit of chamber GAC2, treated groundwater is discharged into a designed infiltration zone. Further details on the infiltration zone are provided in Figure S4 in the Supporting Information.

The interconnecting pipes were provided with valves that allowed the operator to bypass individual chambers (for maintenance purposes) and with taps for sampling water at the entrance and exit of each chamber. Reaction chambers had two sampling points (referred as A and B), each comprising two monitoring wells at approximately 1.6 and $2.6 \mathrm{~m}$ deep (Figure 2).

The SEREBAR system was installed between February and May 2004.

Monitoring and Sampling. Continuous, fully automated monitoring of water level in the chambers, groundwater flow rate and quality parameters ( $\mathrm{pH}$ and conductivity) throughout the SEREBAR system, air flow in the sparging system, and gas analysis $\left(\mathrm{CO}_{2}, \mathrm{CH}_{4}, \mathrm{O}_{2}\right)$ from within the chamber headspace was recorded on a datalogger.

Intermittent monitoring for groundwater chemistry was also carried out during site visits. Monitoring started 2 months after completion of the SEREBAR installation and continued with decreasing frequency from two monthly intervals during the first year to three monthly intervals during the second year. Field monitoring comprised of manual determination of water levels in the chambers, gas analysis from the monitoring wells headspace within the chambers, and groundwater sampling at several points within the SEREBAR. Basic water chemistry parameters were determined in the field for $\mathrm{pH}$ (Hanna Instruments electrode HI 9025C), ORP (Hanna Instruments electrode HI 9025C), dissolved oxygen (Hanna Instruments electrode HI 9145), and Specific Conductance (Hanna Instruments electrode HI 9835). ORP values were then normalized to redox potential (Eh) values by adding $220 \mathrm{mV}$ to correct for the potential of the reference electrode
TABLE 1. Summary of the Operational Parameters of the Barrier over Time

\section{groundwater
flow rate}

(L/d)

\begin{tabular}{|c|c|}
\hline Jul 04 & 520 \\
\hline Oct 04 & 320 \\
\hline Nov 04 & 320 \\
\hline Dec 04 & 520 \\
\hline Jan 05 & $520(10000)$ \\
\hline Feb 05 & 4000 \\
\hline May 05 & 1700 \\
\hline Oct 05 & $\begin{array}{l}0 \text { (pump } \\
\text { malfunction) }\end{array}$ \\
\hline Nov 05 & 1700 \\
\hline Jan 06 & 1000 \\
\hline Jul 06 & 1000 \\
\hline
\end{tabular}

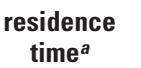

(d)

12
19
19
12
$19(0.6)$
1.5
3.6

3.6

6.1

6.1

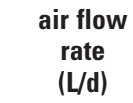

$288-576$

$576-864$

864

864

0 (air compressor

864

malfunction)

864

864
${ }^{a}$ Residence time in individual chambers.

(Ag-AgCl). Gas analysis comprised $\mathrm{CO}_{2}, \mathrm{CH}_{4}, \mathrm{O}_{2}, \mathrm{H}_{2} \mathrm{~S}, \mathrm{CO}$, HCN (Multigas analyzer Data LMSxi, Gas Data Ltd., U.K.) and volatile organic compounds (VOCs) (Minirae 2000 Photo Ionization Detector). Groundwater samples for laboratory analysis were collected from the interconnecting pipes (Figure 2) and stored at $4{ }^{\circ} \mathrm{C}$ until analysis within 10 days at a contract laboratory (MCERTS accredited laboratory).

Laboratory Analysis. PAHs were analyzed by GC-MS (modified U.S. EPA Method 8100) (17) and BTEX by GC-FID (modified U.S. EPA Method 5030) (17). Phenols and cresols were analyzed by HPLC (SCA Method 17.7) (18). The Kone analyzer was used for the analysis of $\mathrm{SO}_{4}{ }^{2-}$ (APHA Method 4500E), $\mathrm{S}^{2-}$ (APHA Method 4500B\&C), $\mathrm{NO}_{3}{ }^{-}$and $\mathrm{NO}_{2}{ }^{-}$(APHA Method 4500H) (19), and $\mathrm{NH}_{4}^{+}$(BSI Method 6068-2.11) (20). Total and free (easily liberatable) cyanide were determined using the "Skalar SANS+System" Segmented Flow analyzer (APHA Method 4500A,B,C,I,M) (19). Major cations and heavy metals were analyzed by Flame-Photometer and ICP-MS (APHA Method 4500E) and major anions by ion chromatography (APHA Method 2310B) (19).

SEREBAR Operation and Maintenance. Table 1 summarizes the operational parameters (groundwater flow rate, residence time in each chamber, airflow rate) of the SEREBAR over time. In January 2006, the original interceptor was replaced with a fully sealed unit to reduce passive aeration. This precaution, together with an increase in flow rate, allowed a more efficient capture of the contaminant load within the reaction chambers and more closely followed the initial design recommendations. In October 2005 the pump malfunctioned, and, after repair work, the SEREBAR ran again in November 2005. Water level monitoring confirmed that groundwater was flowing under gravity through the six reactive chambers of the SEREBAR. Artificial aeration in chambers S2 and S3 ceased between May 2005 and June 2005, following a malfunction in the air compressor. After this time the air flow rate was set at $864 \mathrm{~L} / \mathrm{d}$.

\section{Results and Discussion}

Groundwater Chemistry. The major ion chemistry for site groundwater, prior to entering the interceptor of the SEREBAR, was dominated by calcium bicarbonate with lesser but significant levels of sodium and sulfate (Table S5a in the Supporting Information). The data was consistent with the background chemistry for up-gradient wells proximal to the SEREBAR, sampled prior to its installation (Table S5b in the Supporting Information).

The $\mathrm{pH}$ was invariant, with most values ranging from 6.7 to 7.7 for all sampling events (Figure S6a in the Supporting Information). No significant $\mathrm{pH}$ differences between the 

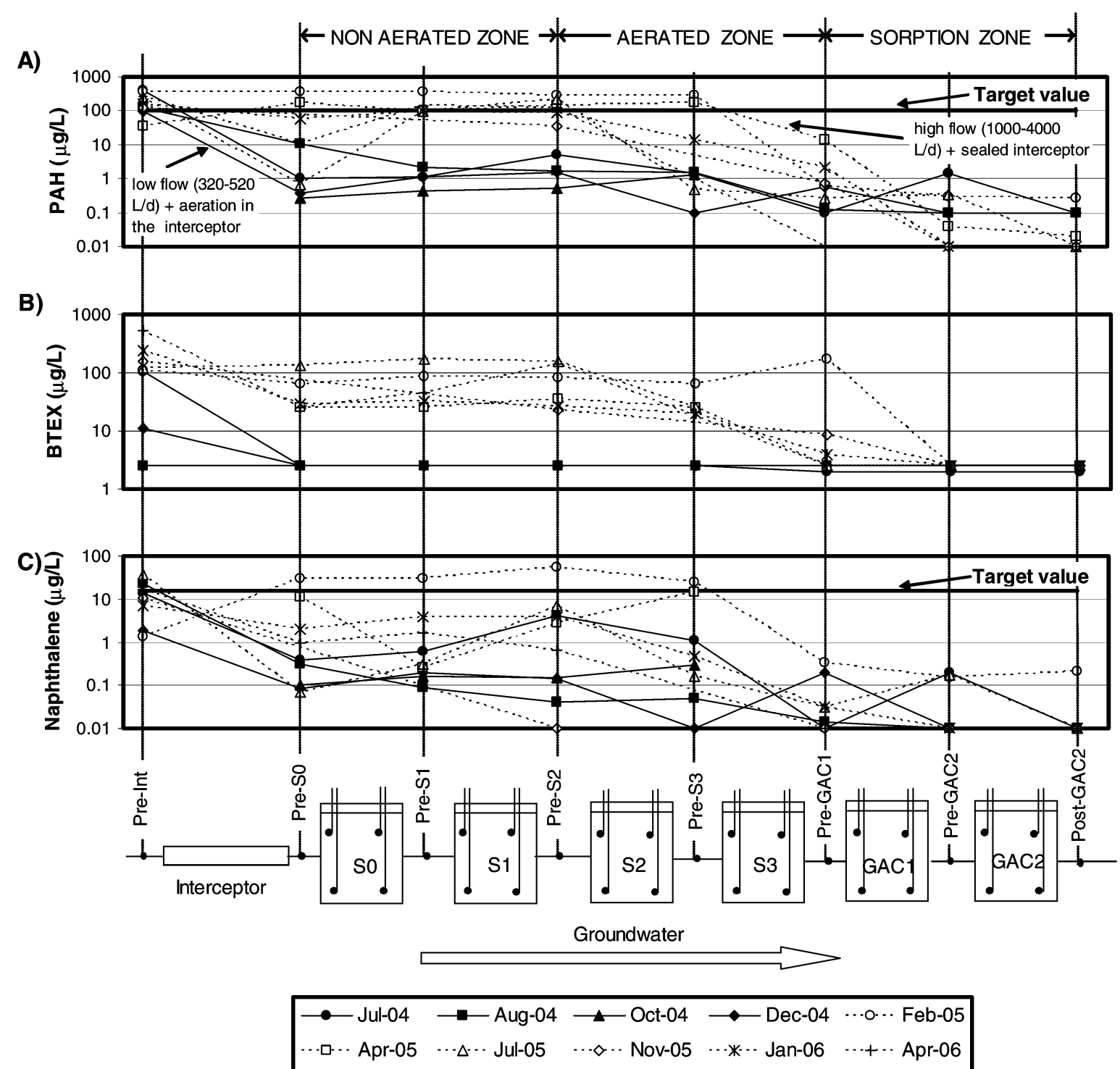

FIGURE 3. Evolution of contaminants of concern: (A) PAH, (B) BTEX, and (C) naphthalene across the barrier for each sampling event. Solid lines indicate concentrations with the original interceptor operating at the design flow rates (before Jan-05), and dashed lines indicate concentrations with the fully sealed interceptor operating at higher flow rates.

aerobic and anaerobic zones were detected. Electric conductivities varied mostly in the range of $600-850 \mu \mathrm{S} / \mathrm{cm}$, except in Jul-04, Oct-04, and Jan-06, when lower ranges were observed $(430-630 \mu \mathrm{S} / \mathrm{cm})$

Prior to the replacement of the interceptor, initial measurements indicated dissolved oxygen (DO) ranged between $2 \mathrm{mg} / \mathrm{L}$ and $4 \mathrm{mg} / \mathrm{L}$ prior to entering the first chamber (S0). This was reduced to $<2 \mathrm{mg} / \mathrm{L}$ with the emplacement of the new fully sealed interceptor (Figure S6b in the Supporting Information). DO declined as groundwater flowed through the anaerobic chamber (mostly $<0.2 \mathrm{mg} / \mathrm{L}$ ) in both $\mathrm{S} 0$ and $\mathrm{S} 1$. As the result of artificial aeration within the chambers S2 and S3, DO concentrations increased slightly (generally from $<0.2$ to $2 \mathrm{mg} / \mathrm{L}$ ). The low DO concentrations in the aerobic chambers (well below the known saturation for $\mathrm{O}_{2}$ in water, ca. $8 \mathrm{mg} / \mathrm{L}$ ), combined with the removal of organic contaminants, indicated that the $\mathrm{O}_{2}$ injected was sufficient for PAHs biodegradation but not in excess. The consumption of $\mathrm{O}_{2}$ to concentration $<2 \mathrm{mg} / \mathrm{L}$ was observed also at higher groundwater and air flow rates. No vertical profiles were observed at the top and bottom of the chambers.

The redox potential (Eh) was generally between $-50 \mathrm{mV}$ and $+250 \mathrm{mV}$ in chambers S0 and S1, with a slight increase observed following flow through the aerated zone (Eh generally between $+170 \mathrm{mV}$ and $+400 \mathrm{mV}$ ). Eh in chambers GAC1 and GAC2 slightly declined to values between $+50 \mathrm{mV}$ and $+250 \mathrm{mV}$, indicating development of reducing conditions in these chambers (Figure S6c in the Supporting Information). No significant differences were observed between Eh in shallow and deep monitoring wells within the chambers.

Groundwater temperature was between 5.5 and $12{ }^{\circ} \mathrm{C}$ in winter months and between 16 and $19^{\circ} \mathrm{C}$ in summer months.

Inlet Concentrations. During a 2-year sampling period, the concentrations of the 16 targeted-USEPA PAHs at the entrance to the interceptor fluctuated between $40 \mu \mathrm{g} / \mathrm{L}$ and $401 \mu \mathrm{g} / \mathrm{L}$ (Figure 3a). BTEXs were observed between $<0.01$ $\mu \mathrm{g} / \mathrm{L}$ and $529 \mu \mathrm{g} / \mathrm{L}$ (Figure $3 \mathrm{~b}$ ). Naphthalene, which was found to be the dominant PAH in the site groundwater (15), entered the SEREBAR at concentrations between 1.4 and $38 \mu \mathrm{g} / \mathrm{L}$ (Figure 3c). Phenols and cresols were always below detection limits $(<10 \mu \mathrm{g} / \mathrm{L})$ as well as cyanide $(<0.5 \mu \mathrm{g} / \mathrm{L})$. The increase in contaminant concentrations entering the reactor was attributed, primarily, to an increase in plume capture following the adjustment to inlet pump speed (increased flow rate through the reactor) and the chemical heterogeneity 
associated with such complex mixtures of contaminants within groundwater.

Low molecular weight (2 rings) PAHs accounted for more than $80 \%$ of the total PAHs entering the barrier. This predominance is not surprising since lighter PAHs exhibit lower hydrophobicities and are more soluble than the heavier and more toxic PAHs, which also bind more tightly to the soil matrix (1). This is noteworthy because bi- and tricyclic PAHs are readily biodegradable and are expected to be removed in the SEREBAR more easily than heavier PAHs.

For the purpose of evaluating and discussing chemical changes across the barrier, a distinction was made between the original interceptor operating at low flow rates (320-520 L/d) (Jul-04-Dec-04) and the new fully sealed interceptor operating at higher flow rates $(1000-4000 \mathrm{~L} / \mathrm{d})$ (Jan-05-Jul06).

Original Interceptor Operating at Low Flow Rates. Under the conditions of low flow rate and prior to the replacement of the interceptor, the removal of PAHs occurred primarily within the interceptor (reduced by $>92 \%$ ) (Figure 3a). This was undoubtedly due to the intrusion of air and the ensuing proliferation of a microbial community responsible for its degradation (15). Such rapid removal of PAHs from groundwater, particularly of the 2-ring PAHs, is in accordance with previous literature (16). The passage of groundwater through the nonaerated zone (chambers S0 and S1) did not significantly decrease $\mathrm{PAH}$ concentration (with a contribution to the overall PAH removal of $<1 \%$, except for Aug-04, for which it was 7\%). A further slight reduction in PAH concentration was noted following the passage of groundwater through the aerated chambers (S2 and S3), with contributions to the overall PAH removal between 1 and $2 \%$ (Figure 3a). In situ analysis of gas from the headspace in the aerated chambers showed VOCs concentrations below $<1 \mathrm{mg} / \mathrm{L}$, indicating that losses of organic compounds due to volatilization were minimal and that biodegradation could be regarded as the dominating removal process. Passage through the sorption zone (GAC1 and GAC2 chambers) led to a further reduction in PAHs concentrations $(<0.01 \mu \mathrm{g} / \mathrm{L})$ prior to discharge (resulting in an overall removal of PAHs >99.9\%). This concentration was well below the target value for discharge compliance set by the Environment Agency.

The concentration profiles for the priority pollutant naphthalene, and also BTEX, across the SEREBAR are shown in Figure 3b,c. Similarity between the profile for PAH concentration was apparent. In relation to naphthalene, concentrations prior to the interceptor ranged from $1.9 \mu \mathrm{g} / \mathrm{L}$ to $23.2 \mu \mathrm{g} / \mathrm{L}$ and fell below $0.4 \mathrm{mg} / \mathrm{L}$ at Pre-S0 (removal $>96 \%$ ). These values declined only very slightly through the biological chambers (S0-S3), with an average concentration of $0.1 \mu \mathrm{g} / \mathrm{L}$ entering the sorption zone. Again, GAC proved effective at sorbing the remaining naphthalene to marginal concentrations $(<0.01 \mu \mathrm{g} / \mathrm{L})$. BTEX removal within the interceptor was in the range of $77-98 \%$, resulting in concentrations below detection limits $(<2.5 \mu \mathrm{g} / \mathrm{L})$ at Pre-S0. The concentrations remained undetectable from Pre-S0 onward.

Fully Sealed Interceptor Operating at High Flows. In January 2005, the interceptor was replaced with a fully sealed unit to prevent passive aeration. Additionally, the flow rate was increased in February 2005 to $4000 \mathrm{~L} / \mathrm{d}$ (Table 1). As shown in Figure 3a, these actions minimized biodegradation in the interceptor. An increase in the concentration of PAHs (from an average of 3.03-104 $\mu \mathrm{g} / \mathrm{L}$ at Pre-S0) entering the SEREBAR also rose following these alterations. These concentrations did not appear to diminish substantially across the anaerobic zone (removals mostly $<22 \%$ ). As groundwater travelled through the aerated chambers $\mathrm{S} 2$ and $\mathrm{S} 3$, a reduction in the concentration of PAHs was apparent (removals $>91 \%$ ), with concentrations at Pre-GAC1 averaging $2.92 \mu \mathrm{g} / \mathrm{L}$. The reduction in PAHs concentration within the aerated chambers occurred in S2 (Jul-05 sampling event), in S3 (Feb-05 and Apr-05), and in both S2 and S3 (Nov-05, Jan-06, and Apr-06). The differences in these concentration profiles may rely on seasonal variations and on adaptations to new flow rates. However, this finding is consistent with the increase in microbial numbers within the aerated chambers (S2 and S3) following the increase in flow rates through the SEREBAR (15). Passage through the sorption zone again led to a further reduction in PAHs concentrations $(<0.26 \mu \mathrm{g} / \mathrm{L})$ prior to discharge. Similarly to the previous operational conditions, the overall removal of PAHs through the SEREBAR was $>99.9 \%$.

The concentration profile for BTEX was again similar to that observed with PAHs. A direct consequence of the increase in flow rates through the barrier was that the BTEX concentrations entering the chambers (Pre-S0) rose from $<2.5 \mu \mathrm{g} / \mathrm{L}$ to an average of $49.75 \mu \mathrm{g} / \mathrm{L}$ (Figure $3 \mathrm{~b}$ ). The passage of groundwater through the unaerated chambers did not substantially decrease the concentrations of BTEX. Similarly to PAHs, anaerobic degradation of BTEX is widely reported, although degradation rates are known to be substantially slower in comparison to aerobic conditions (4). Consequently, at the retention times associated with such increased flow rate $(1000-4000 \mathrm{~L} / \mathrm{d})$, any reduction in contaminant load within this section was not expected. However, as groundwater crossed the aerated chambers, BTEX concentrations declined to an average of $4.38 \mu \mathrm{g} / \mathrm{L}$, indicating a BTEX removal efficiency of $>91 \%$. An exception of this pattern was the Feb05 sampling event, which showed a surprising elevated concentration of $172 \mu \mathrm{g} / \mathrm{L}$. This was attributed to the abrupt increase in flow rate imposed prior to the sampling event (Table 1), resulting in a reduction in residence time within the chambers and insufficient time for the acclimatization necessary for microbial degradation to occur. As with PAHs, BTEXs were further removed within the sorptive zone, with concentrations reduced to $<2.5 \mu \mathrm{g} / \mathrm{L}$ at the post-GAC2 sampling location (overall removal $>95 \%$ ).

The removal of the petroleum constituents in the SEREBAR is comparable to a previous $\mathrm{PRB}$ for the treatment of $\mathrm{n}$-alkanes and BTEX, where removal percentages varied from 63 to $96 \%$ for BTEX and from 54 to $81 \%$ for different n-alkanes fractions (11).

Gas Analysis. Headspace gas within the chambers generally presented a composition very close to that of air, with small increases in $\mathrm{CO}_{2}$ around $0.5 \%(\mathrm{v} / \mathrm{v})$ but with sporadic peaks up to $2 \%(\mathrm{v} / \mathrm{v})$ within $\mathrm{S} 3$. We postulate that the observed increase in $\mathrm{CO}_{2}$ levels was indicative of microbial activity, especially within the aerated chambers. This finding is consistent with the PAHs and BTEX removals described above and with the higher microbial populations found in S2 and S3 following increase in flow rates (15).

Changes in Potential Indicators of Redox Conditions in the SEREBAR. The development of anaerobic/aerobic conditions can be reflected in other redox sensitive species such as the sulfate/sulfide and nitrate/ammonium couples.

Sulfate concentrations remained largely unchanged for all sampling events (Figure 4a). This pattern was expected since Eh measurements were generally higher than those associated with sulfate reduction (Eh between -100 and -300 $\mathrm{mV})$. Sulfide was always detected at low levels $(<0.1 \mathrm{mg} / \mathrm{L}$, mostly $<0.05 \mathrm{mg} / \mathrm{L}$ ).

The oxidized/reduced nitrogen species reflected well the anaerobic/aerobic conditions developed within the SEREBAR system. The overall profile of $\mathrm{N}$-compounds along the barrier differed depending upon the intrusion of air at the interceptor. With passive aeration in the interceptor (i.e., during the first 6 months of operation), $\mathrm{NO}_{3}{ }^{-}$and $\mathrm{NO}_{2}{ }^{-}$were sporadically found in Pre-S0 at concentrations around $5 \mathrm{mg} / \mathrm{L}$ (as N) (Figure 4b). It should be noted that these oxidized N-species were not originally present in the contaminated plume. Their 


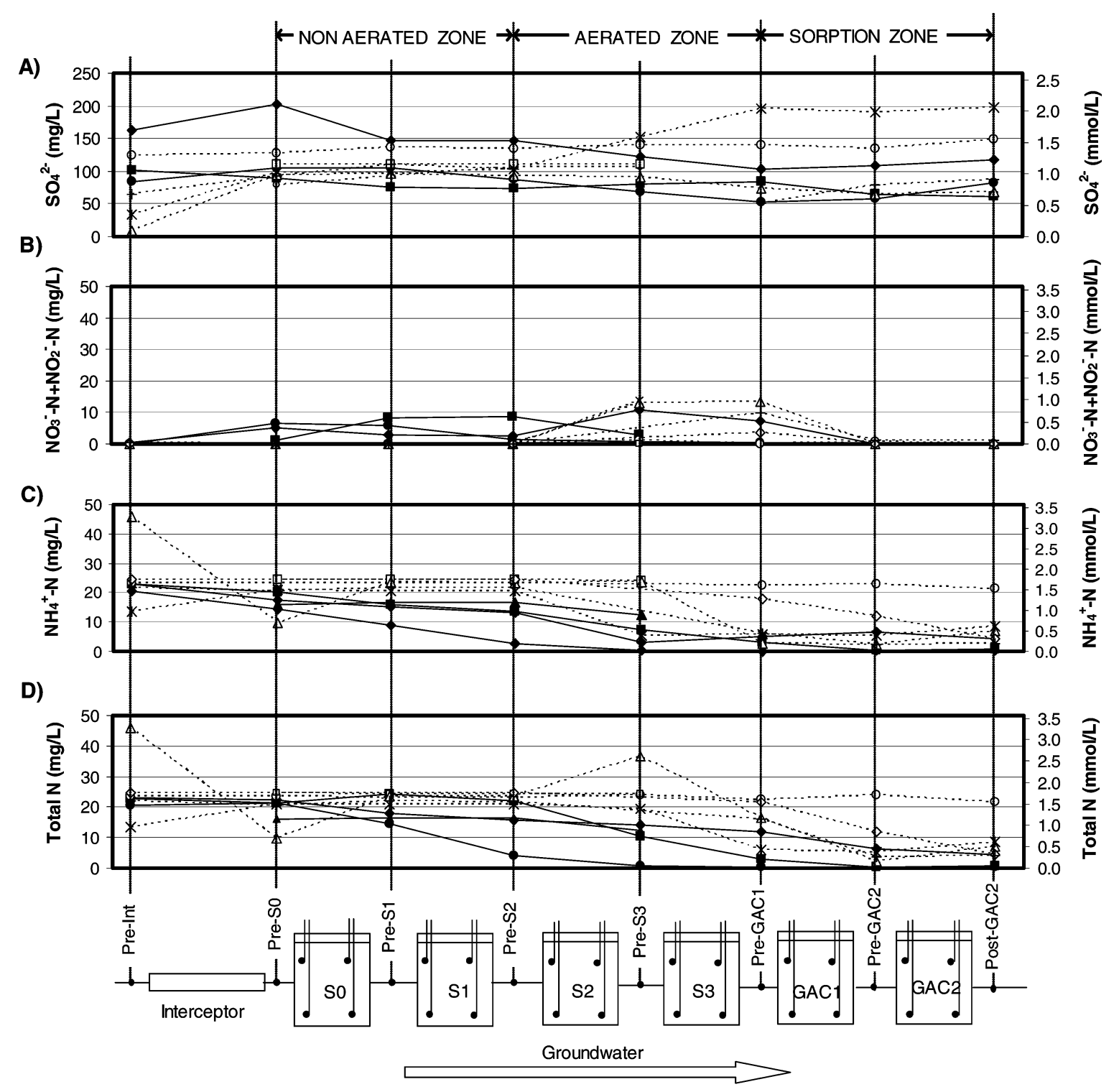

\begin{tabular}{|c|c|c|c|c|}
\hline$\longrightarrow-$ Jul-04 & $\longrightarrow$ - Aug-04 & $\longrightarrow$ Oct-04 & $\multimap$ Dec-04 & $\cdots$ o $\cdots$ Feb-05 \\
\hline - A A Apr-05 & $\cdots \Delta \cdots$ Jul-05 & $\cdots \diamond \cdots$ Nov-05 & $\cdots * \cdots$ Jan-06 & $\cdots+\cdots$ Apr-06 \\
\hline
\end{tabular}

FIGURE 4. Evolution of redox-sensitive species: (A) sulfate, (B) nitrate + nitrite, (C) ammonium, and (D) total $\mathbf{N}$, across the barrier for each sampling event. Solid lines indicate concentrations with the original interceptor operating at the design flow rates (before Jan-05), and dashed lines indicate concentrations with the fully sealed interceptor operating at higher flow rates.

presence relies on the partial oxidation of $\mathrm{NH}_{4}{ }^{+}$in the interceptor, due to the intrusion of air. Further passage of groundwater through the nonaerated chambers resulted in a gradual decrease of these oxidized $\mathrm{N}$-species to $<1.0 \mathrm{mg} / \mathrm{L}$ (as $\mathrm{N}$ ), suggesting that denitrification was occurring in S0 and $\mathrm{S} 1$. The fact that $\mathrm{NO}_{3}{ }^{-}$removal occurred with no removal of target contaminants (Figure 3) may be due to the presence of other nontarget organic compounds that are more readily degradable and exert a demand for electron acceptor. The $\mathrm{NO}_{3}{ }^{-}$decrease might also be partially due to $\mathrm{NO}_{3}{ }^{-}$assimilation into biomass (22). As expected, the entrance into the aerated chambers led to an increase of $\mathrm{NO}_{3}{ }^{-}$and $\mathrm{NO}_{2}{ }^{-}$(up to $14 \mathrm{mg} / \mathrm{L}$ as $\mathrm{N}$ ) and the concomitant decrease of $\mathrm{NH}_{4}{ }^{+}$, indicating that the chemical oxidation of $\mathrm{NH}_{4}{ }^{+}$contributed to the consumption of oxygen delivered in chambers S2 and S3. Exceptions to these patterns occurred in Jul-04, when a decrease of $\mathrm{NH}_{4}{ }^{+}$in the nonaerated chambers was observed, and Aug-04, when an unexpected increase in the oxidized nitrogen compounds was observed again in the nonaerated zone. The former indicated the existence of mechanisms responsible for $\mathrm{NH}_{4}^{+}$removal in anaerobic conditions termed Anammox (21), while the latter is most likely associated with the intrusion of air during sample collection.

Once the interceptor was replaced the profiles of $\mathrm{N}$ compounds along the SEREBAR chambers were simpler. With no oxidation of $\mathrm{NH}_{4}^{+}$within the interceptor, all nitrogen entered the anaerobic zone as $\mathrm{NH}_{4}^{+}$and as such crossed the anaerobic zone. The entrance into the aerated chambers resulted in a drop in the $\mathrm{NH}_{4}{ }^{+}$concentration, accompanied by an increase in both $\mathrm{NO}_{3}{ }^{-}$and $\mathrm{NO}_{2}{ }^{-}$(up to $\sim 13 \mathrm{mg} / \mathrm{L}$ ). Exceptions to this pattern were the Feb-04 sampling event, when $\mathrm{NH}_{4}{ }^{+}, \mathrm{NO}_{3}{ }^{-}$, and $\mathrm{NO}_{2}{ }^{-}$concentrations remained unchanged across the SEREBAR, and the Jul-05 sampling event, when a decrease in the concentration of $\mathrm{NH}_{4}{ }^{+}$was observed within the interceptor. The former is attributed to the abrupt increase in flow rate imposed prior to the sampling event (Table 1), while the latter is not fully understood. 
Figure $4 \mathrm{~d}$ shows the profile of total inorganic nitrogen $\left(\mathrm{NH}_{4}{ }^{+}+\mathrm{NO}_{3}{ }^{-}+\mathrm{NO}_{2}{ }^{-}\right)$. The reduction in total $\mathrm{N}$ is achieved by the passage of groundwater through the SEREBAR, probably mainly as a result of the nitrification and denitrification processes, discussed above.

In summary, as demonstrated within our initial laboratory-based treatability work, the SEREBAR proved to be effective at removing organic contaminants from a groundwater impacted by coal-tar constituents. The gate of the barrier consisted of an interceptor and three separate reactive zones consecutively based on anaerobic/aerobic degradation and sorption onto GAC. During the 2 years of operation, the SEREBAR removed PAHs and BTEX at $>95 \%$ levels. Since the contaminated plume provides the organic carbon necessary to promote bacterial activity, there is no requirement for organic substrate as filling reactive material in the chambers nor external supplementation. Exhaustion of reactive material can arise from saturation of the sorptive sites of the GAC. However, taking into account laboratory results on the sorption capacity of GAC and the concentration at the entrance of the sorption chambers, replacement would not be necessary for at least 10 years. Issues that must be considered are the possible losses of porosity due to biomass growth, which can negatively impact the hydraulic performance of the SEREBAR. Further monitoring will be conducted biannually to ensure the long-term effectiveness of the SEREBAR in managing the risks associated with the FMGP.

Sequenced reactive barriers offer effective risk management strategies for sites with complex contaminant groundwater plumes, both organic and inorganic, due to the ease in which chamber fill material can be altered.

\section{Acknowledgments}

The authors acknowledge the contributions made by the SEREBAR Team, Parsons Brinckerhoff, National Grid Property Holdings (especially P. Daly), First Faraday, DTI, and Keller Ground Engineering. We also thank four anonymous reviewers for their constructive comments and questions.

\section{Supporting Information Available}

Location of the monitoring wells installed at the site for the initial site characterization (Figure S1), hydraulic conductivity determined at each well following slug pump tests (Table S2), potentiometric surface map of the flow field once the SEREBAR system was installed (Figure S3), design of the infiltration zone (Figure S4), comparison of the major ion chemistry for site groundwater crossing the SEREBAR system and groundwater sampled during the initial site characterization (Table S5a,b), and evolution of (a) pH, (b) DO, and (c) Eh across the barrier for each sampling event (Figure S6). This material is available free of charge via the Internet at http://pubs.acs.org.

\section{Literature Cited}

(1) Haeseler, F.; Blanchet, D.; Druelle, V.; Werner, P.; Vande Casteele, J.P. Ecotoxicological assessment of soils of former manufactured gas plant sites: Bioremediation potential and pollutant mobility. Environ. Sci. Technol. 1999, 33, 4379-4384.

(2) Zamfirescu, D.; Grathwohl, P. Occurrence and attenuation of specific organic compounds in the groundwater plume at a former gasworks site. J. Contam. Hydrol. 2001, 53, 407-427.

(3) Abrams, R. H.; Loague, K. Legacies from three former manufactured-gas plants: impacts on groundwater quality. Hydrogeol. J 2000, 8, 594-607.

(4) Landmeyer, J. E.; Chapelle, F. H.; Petkewich, M. D.; Bradley, P. M. Assessment of natural attenuation of aromatic hydrocarbons in groundwater near a former manufactured-gas plant, South
Carolina, USA. Environ. Geol. 1997, 34, 279-292.

(5) Schmitt, R.; Langguth, H. R.; Püttmann, W.; Rohns, H. P.; Eckert, P.; Schubert, J. Biodegradation of aromatic hydrocarbons under anoxic conditions in a shallow sand and gravel aquifer of the Lower Rhine Valley, Germany. Org. Geochem. 1996, 25, 41-50.

(6) Gogoi, B. K.; Dutta, N. N.; Goswami, P.; Krishna, Mohan, T. R. A case study of bioremediation of petroleum-hydrocarbon contaminated soil at a crude oil spill site. Adv. Environ. Res. 2003, 7, 767-782.

(7) Guerin, T. F. The differential removal of aged polycyclic aromatic hydrocarbons from soil during bioremediation. Environ. Sci. Pollut. Res. 2000, 7, 19-26.

(8) Bass, D. H.; Hastings, N. A.; Brown, R. A. Performance of air sparging systems: A review of case studies. J. Hazard. Mater. 2000, 72, 101-119.

(9) Tiehm, A.; Stieber, M.; Werner, P.; Frimmel, F. Surfactantenhanced mobilization and biodegradation of polycylic aromatic hydrocarbons in manufactured gas plant soil. Environ. Sci. Technol. 1997, 31, 2570-2576.

(10) Sharak, Genthner, B. R.; Townsend, G. T.; Lantz, S. E.; Mueller, J. G. Persistence of polycyclic aromatic hydrocarbon components of creosate under anaerobic enrichment conditions. Arch. Environ. Contam. Toxicol. 1997, 32, 99-105.

(11) McGovern, T.; Guerin, T. F.; Horner, S.; Davey, B. Design, construction and operation of a funnel and gate in-situ permeable reactive barrier for remediation of petroleum hydrocarbons in groundwater. Water, Air, Soil Pollut. 2002, 136, $11-31$.

(12) CL:AIRE. Laboratory and Field Evaluation of a Bio-Reactive Permeable Barrier for Remediation of Organic Contaminants in Soil and Groundwater, Case Study Bulletin, CSB3, April 2005.

(13) Birke, V.; Burmeier, H.; Rosenau, D. Design, construction, and operation of tailored permeable reactive barriers. Pract. Period. Hazard., Toxic, Radioact. Waste Manage. 2003, 7, 264-280.

(14) Shifrin, N. S.; Beck, B. D.; Gauthier, T. D.; Chapnick, S. D.; Goodman, G. Chemistry, Toxicology, and human health risk of cyanide compounds in soils at former manufactured gas plant sites. Regul. Toxicol. Pharmacol. 1996, 23, 106-116.

(15) Ferguson, A. S.; Huang, W. E.; Lawson, K. A.; Doherty, R.; Gibert, O.; Dickson, K. W.; Whiteley, A. S.; Kulakov, L. A.; Thompson, I. P.; Kalin, R. M.; Larkin, M. J. Microbial analysis of soil and groundwater from a gasworks site and comparison to a sequenced biological reactive barrier remediation process (SEREBAR). J. Appl. Microbiol. 2007, 102, 1127-1238.

(16) Rasmussen, G.; Fremmersvik, G.; Olsen, R. A. Treatment of creosote-contaminated groundwater in a peat/sand permeable barrier - a column study. J. Hazard. Mater. 2002, B93, 285306.

(17) USEPA (U.S. Environmental Protection Agency). Methods for Chemical Analysis of Water and Wastes, Environmental Monitoring and Support Laboratory; Office of Research and Development, U.S. EPA: Cincinnati, OH, 1983.

(18) SCA (Standing Committee of Analysts). The Determination of Microgram and Submicrogram Amounts of Individual Phenols in River and Potable Waters (book 124). Methods for the examination of waters and associated materials; Environmental Agency: London, U.K., 1988.

(19) APHA (American Public Health Association). Standard Methods for the Examination of Water and Wastewater, 20th ed.; American Water Works Association (AWWA), Water Pollution Control Federation: Washington, DC, 1999.

(20) BSI (British Standards Institution) British Standard Method 60682.11: Water quality. Physical, chemical and biochemical methods. Determination of ammonium: manual spectrometric method; London, U.K., 1984.

(21) Robertson, W. D.; Blowes, D. W.; Ptacek, C. J.; Cherry, J. A. Longterm performance of in situ reactive barriers for nitrate remediation. Ground Water 2000, 38, 689-695.

(22) Pilcher, H. Microbiology: Pipe dreams. Nature 2005, 437, 12271228.

Received for review February 21, 2007. Revised manuscript received May 11, 2007. Accepted July 9, 2007.

\section{ES071527F}

